\title{
Preparation, Characterization, Dielectric, Piezoelectric and Ferroelectric Properties of Yttrium and Praseodymium Doped Lead Titanate Ceramics
}

\author{
Karan Singh, Vishal Singh, Rashmi Gupta and Krishen Kumar Bamzai \\ Crystal Growth \& Materials Research Laboratory, Department of Physics and Electronics, University of Jammu, Jammu, India
}

Received: October 10, 2014 / Accepted: October 24, 2014 / Published: October 25, 2014.

\begin{abstract}
Rare earth double doped lead titanate with general formula $\mathrm{Pb}_{1-\mathrm{x}} \operatorname{Pr}_{\mathrm{x}} \mathrm{Ti}_{1-\mathrm{y}} \mathrm{Y}_{\mathrm{y}} \mathrm{O}_{3}$ where $\mathrm{x}$ (praseodymium) $=0.02,0.04,0.06$, 0.08 and $\mathrm{y}(\mathrm{yttrium})=0.02$ was synthesized by solid state reaction technique. X-ray diffraction analysis confirms single phase formation with perovskite structure having tetragonal phase. Micro-structural analysis shows formation of dense micro-structure with grain size calculated using average line intercepted method. Dielectric behavior as a function of temperature was found to decrease with Pr substitution. The diffusivity in the dielectric behavior was observed in all the compositions. Piezoelectric coefficient $d_{33}$ and $g_{33}$ was determined with increase in compositions of Pr substituent. The ferroelectric property was observed at room temperature and the value of remanent polarization $\left(\mathrm{P}_{\mathrm{r}}\right)$, spontaneous polarization $\left(\mathrm{P}_{\mathrm{s}}\right)$ and $\left(\mathrm{E}_{\mathrm{C}}\right)$ coercive field was calculated.
\end{abstract}

Key words: Ceramics, ferroelectric, lead titanate, solid state reaction.

\section{Introduction}

Lead titanate (PT) ceramics exhibit many attractive properties, which makes it possible for devices and in many electronic applications [1]. Lead titanate belongs to $\mathrm{ABO}_{3}$ type perovskite form which is one of the most important classes of ferroelectric materials with non linear electro-optic properties [2]. PT has been used as a model system to understand various phenomena related to cubic to tetragonal phase transition. The transition, which takes place at about $490{ }^{\circ} \mathrm{C}$ from high temperature cubic phase $(\mathrm{Pm} 3 \mathrm{~m})$ to a tetragonal (P4mm) ferroelectric phase and is accompanied by an abrupt anomaly in electric permittivity, the spontaneous polarization and specific heat etc. The ferroelectric phase transition in lead titanate at $490{ }^{\circ} \mathrm{C}$ has attracted continuing interest since it was

Corresponding author: Krishen Kumar Bamzai, Ph.D., professor, research fields: crystal growth, ceramic preparation, characterization, properties of complex oxide and rare earth. E-mail:kkbamz@yahoo.com. investigated by Shirane and Hoshino [3] in 1951. Lead titanate ceramics prepared by firing technique is too fragile because of its large lattice anisotropy (c/a) of 1.064 [4]. A dense and hard PT ceramics can be prepared either by modifying the processing condition i.e., appropriate milling and sintering techniques $[5,6]$ or by adding suitable dopants [7-9]. Among the dopants, the substitution of lead by alkaline and rare earth metals results in the large anisotropy of piezoelectric and higher electromechanical anisotropy $\left(\mathrm{K}_{\mathrm{t}} / \mathrm{K}_{\mathrm{p}}\right)[10,11]$. This large ratio of thickness to lateral electromechanical coupling coefficient in PT is useful in high frequency transducer and high temperature applications such as surface acoustic wave (SAW) devices and piezoelectric transformers [1, 12, 13]. Similar properties were also obtained by substituting calcium ions with $\mathrm{Sm}$ modified $\mathrm{PbTiO}_{3}$ [14]. In order to improve the dielectric, ferroelectric and piezoelectric properties efforts have been extended by way of controlling grain growth and designing 
microstructure inhomogenity. Substitution of both isovalent and aliovalent cation for the host ones in perovskite lattice plays an important role in the modification mechanisms. Modified PT ceramics has received a great deal of attention as promising material for transducer arrays $[9,15]$.

The piezoelectric and mechanical properties of modified PT ceramics are important for use in the generation of high power ultrasonic [8]. Thus, PT ceramics becomes material of interest because of piezoelectric properties which is the result of spontaneous polarization. This polarization is due to high crystalline anisotropy which on the other hand gives rise to intergranular stresses.

It was reported $[16,17]$ that substitutions of $\operatorname{Pr}$ and La on A-site of PT ceramics significantly improve the density, dielectric, piezoelectric and electromechanical properties of these ceramics. Based on these investigations, we have in the present case chosen praseodymium and yttrium as co-dopants to modify the relative concentration of lead titanate. Praseodymium with ionic radii $1.09 \AA$ replaces lead with ionic radii $1.20 \AA$ whereas yttrium $0.93 \AA$ replaces titanium $0.90 \AA$. Thus, the present investigations deal with the effect of Pr and $\mathrm{Y}$ as co-dopants on A and B-site of the lead titanate respectively. To the best of author knowledge, no such work on rare earth co-doped lead titanate is reported with compositions $\mathrm{Pb}_{1-\mathrm{x}} \mathrm{Pr}_{\mathrm{x}} \mathrm{Ti}_{1-\mathrm{y}} \mathrm{Y}_{\mathrm{y}} \mathrm{O}_{3}$ (where $\mathrm{x}=0.02,0.04,0.06,0.08$ and $\mathrm{y}=0.02)$.

\section{Materials and Method}

The stoichiometric amounts of $\mathrm{PbO}(99 \%), \mathrm{Y}_{2} \mathrm{O}_{3}$ (99.9\%), $\mathrm{TiO}_{2}$ (99\%), $\mathrm{Pr}_{6} \mathrm{O}_{11}$ (99.5\%) (High grade materials from $\mathrm{S}$. d. fine-CHEM limited) was mixed in triple distilled water for $48 \mathrm{~h}$ for the preparation of $\mathrm{Pb}_{1-\mathrm{x}} \mathrm{Pr}_{\mathrm{x}} \mathrm{Ti}_{1-\mathrm{y}} \mathrm{Y}_{\mathrm{y}} \mathrm{O}_{3}$ with $\mathrm{x}$ (praseodymium) $=0.02,0.04$. $0.06,0.08$ and $y$ (yttrium) $=0.02$. The solution was then dried in an oven at $150{ }^{\circ} \mathrm{C}$. After drying the material was ground into fine powder in an agate mortar and calcined in the closed crucible in the form of loosely packed blocks at temperature of about $800-850{ }^{\circ} \mathrm{C}$ for $2 \mathrm{~h}$. The fine calcined powder was granulated with few drops of polyvinyl alcohol (PVA) as binder and then pressed into pallets of 10-12 mm diameter and 1-2 mm thickness by using $\mathrm{KBr}$ die set and a hydraulic press under uniaxial pressure 150-200 MPa. The cold pressed pallets of modified lead titanate were then finally sintered at $1,100{ }^{\circ} \mathrm{C}$ for $2 \mathrm{~h}$. The sintering was carried out in a closed platinum crucible containing $\mathrm{PbO}$ in addition to sintering material in order create partial pressure of lead atmosphere to prevent excessive loss of lead from the samples. The sintered final product was then characterized and its physico-chemical properties studied. The phase composition was detected by X-ray powder diffraction (D8 Advanced Bruker instrument with $\mathrm{Cu} \mathrm{K \alpha}$ radiation $1.54 \AA$ ) at a scanning rate of $1 \mathrm{~min}$. The morphology of the sample was observed using JEOL-840 scanning electron microscope (SEM). The elemental composition was determined by energy dispersive X-ray analysis (EDX) method. The dielectric measurements were carried out as a function of temperature by using 4192A-LF impedance analyzer working in the range of $5 \mathrm{~Hz}$ to $13 \mathrm{MHz}$, a microprocessor based furnace fitted with a temperature controller and a specially designed two terminal sample holder provided with a jacket for water circulation during heating. The control measurement and analysis was managed through computer with Agilent software. This instrument directly gives the values of capacitance $(C)$ and so dielectric constant $\left(\varepsilon^{\prime}\right)$ is calculated by using relation:

$$
\varepsilon^{\prime}=\frac{C t}{\varepsilon_{0} A}
$$

where, $C$ is the capacitance; $t$ is the thickness; $\varepsilon_{0}$ is the absolute permittivity whose value is $8.854 \times 10^{-12} \mathrm{Fm}^{-1}$ and $A$ is the area. The spontaneous polarization of a ferroelectric material was measured by hysteresis loop by using Sawyer-Tower circuit by the application of the a.c field. The Berlincourt meter (PM 300) was used for piezoelectric $\left(d_{33}\right)$ measurements. 


\section{Results and Discussion}

\subsection{X-Ray Diffraction (XRD) Analysis}

Fig. 1 shows X-ray diffraction (XRD) pattern of $\operatorname{Pr}$ and $\mathrm{Y}$ co-doped lead titanate ceramics with composition $\mathrm{Pb}_{1-\mathrm{x}} \mathrm{Pr}_{\mathrm{x}} \mathrm{Ti}_{1-\mathrm{y}} \mathrm{Y}_{\mathrm{y}} \mathrm{O}_{3}$ where $\mathrm{x}=0.02,0.04$, $0.06,0.08$ and $y=0.02$. The phase formation was confirmed by comparing the patterns with standard JCPDS file (6-0452) for $\mathrm{PbTiO}_{3}$. The XRD analysis showed that all the four compositions are single phase with tetragonal structure. The lattice parameters (c and a) and crystal tetragonality (c/a) were calculated from XRD data and is given in Table 1.

The variation of lattice constants as a function of change in compositions for PT by Pr and $\mathrm{Y}$ is shown in Fig. 2. It is seen that there is relative decrease in the value of "c" and nominal increase in the value of "a" as amount of modification on A-site increases. The crystal tetragonality c/a, is observed to decrease with the increase in substitution content resulting in hard and dense ceramics except for $\mathrm{x}=0.08$ and $\mathrm{y}=0.02$ compositions, where there is a slight increase [18].

Many researchers have also reported decrease in lattice tetragonality on various modified PT ceramics [19-21]. Introduction of $\mathrm{La}^{3+}$ and $\mathrm{Ca}^{2+}$ into $\mathrm{Pb}$-site of PT perovskite structure causes strong reduction in "c" with no significant change in the "a" parameter as reported by Mendiola et al. [21] and Tickoo et al. [22], which is similar to our observation. Change in lattice parameter and lattice tetragonality depends upon the ionic radii of the dopant. Increase in ionic radius of the dopant decreases the crystal tetragonality [21]. The theoretical density, experimental density, relative density and porosity have been calculated with the help of XRD and is given in the Table 1.

\subsection{Microstructural Study}

The grain size in lead titanate is greatly influenced by the content of additives and is one of the important factor influencing the poling behavior, ferroelectric and piezoelectric properties. The microstructure of all the compositions are shown in Figs. 3a-3d and the average grain size was measured by linear intercept method and is given in Table 1. It can be seen from the micrographs that all the compositions show uniform grain growth and grain compactions with well defined grain boundaries. The compositional analysis was carried out by the energy dispersive analysis (EDAX) using X-ray detector attached to the scanning electron microscope (SEM) instrument. The EDAX spectrum of one of the composition with $\mathrm{x}=\mathrm{y}=0.02$ is shown in Fig. 4 with corresponding data shown as inset in the same figure.

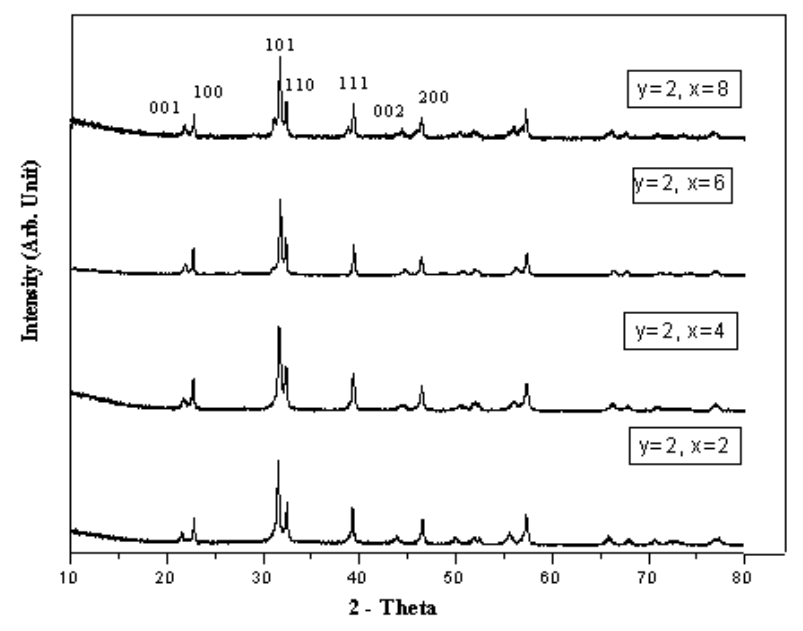

Fig. 1 XRD pattern of $\operatorname{Pb}_{1-\mathrm{x}} \mathrm{Pr}_{\mathrm{x}} \mathrm{Ti}_{1-\mathrm{y}} \mathrm{Y}_{\mathrm{y}} \mathrm{O}_{3}$ compositions.

Table 1 Lattice constants (a \& c), X-ray density, experimental density, relative density, porosity and grain size for rare earth double doped lead titanate with compositions $\operatorname{Pb}_{1-\mathrm{x}} \operatorname{Pr}_{\mathrm{x}} \mathrm{Ti}_{1-\mathrm{y}} \mathrm{Y}_{\mathrm{y}} \mathrm{O}_{3}$ where $\mathrm{x}=0.02,0.04,0.06,0.08$ and $y=0.02$.

\begin{tabular}{lllllllll}
\hline $\mathrm{x}=\mathrm{Pr}, \mathrm{y}=\mathrm{Y}$ & $\mathrm{c}(\AA)$ & $\mathrm{a}(\AA)$ & $\mathrm{c} / \mathrm{a}$ & $\rho_{\mathrm{x}-\mathrm{ray}(\mathrm{g} / \mathrm{cc})}$ & $\rho_{\mathrm{exp}(\mathrm{g} / \mathrm{cc})}$ & $\begin{array}{l}\text { Relative } \\
\text { density }(\%)\end{array}$ & Porosity & $\begin{array}{l}\text { Grain Size } \\
(\mu \mathrm{m})\end{array}$ \\
\hline $\mathrm{x}=0.02, \mathrm{y}=0.02$ & 4.134 & 3.890 & 1.062 & 8.04 & 6.42 & 79.82 & 20.17 & 0.548 \\
$\mathrm{x}=0.04, \mathrm{y}=0.02$ & 4.077 & 3.909 & 1.043 & 8.11 & 6.42 & 79.06 & 22.16 & 0.353 \\
$\mathrm{x}=0.06, \mathrm{y}=0.02$ & 4.053 & 3.910 & 1.036 & 8.21 & 6.33 & 77.15 & 22.84 & 0.352 \\
$\mathrm{x}=0.08, \mathrm{y}=0.02$ & 4.068 & 3.906 & 1.041 & 8.25 & 6.33 & 76.72 & 23.27 & 0.585 \\
\hline
\end{tabular}




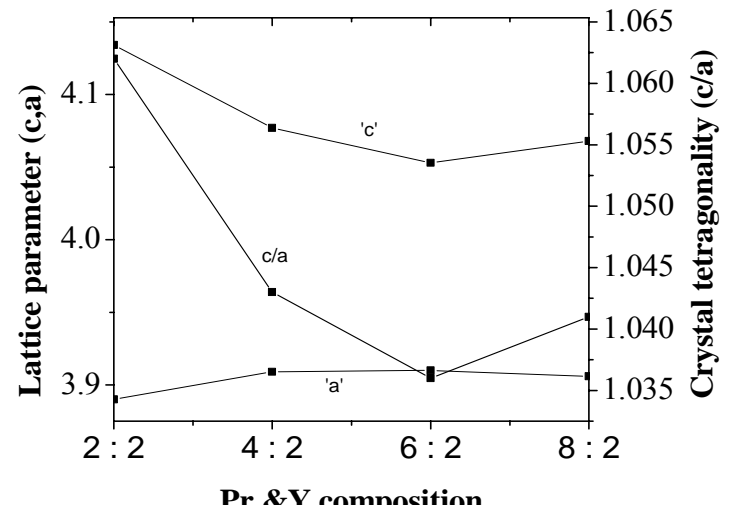

Fig. 2 Lattice parameter and crystal tetragonality versus Pr and $Y$ concentration lattice.
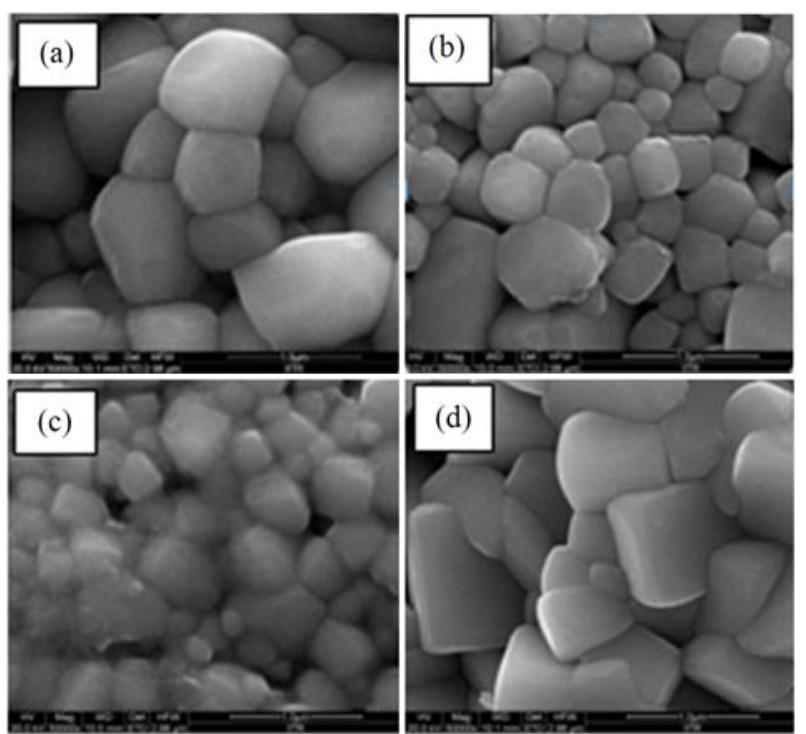

Fig. 3 Scanning electron micrograph of $\operatorname{Pb}_{1-\mathrm{x}} \mathrm{Pr}_{\mathrm{x}} \mathrm{Ti}_{1-\mathrm{y}} \mathrm{Y}_{\mathrm{y}} \mathrm{O}_{3}$ compositions (a) $x=y=2 \%$, (b) $x=4, y=2 \%$, (c) $x=6, y=2 \%$ and (d) $x=8, y=2 \%$.

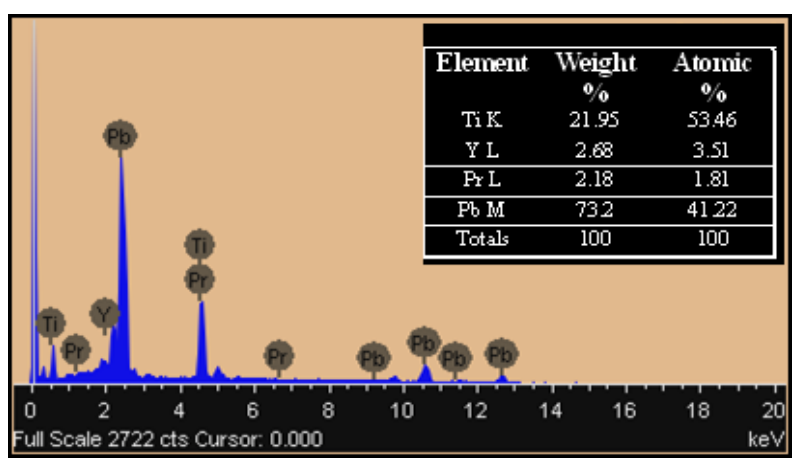

Fig. 4 EDS pattern showing the constituent elements present for composition $x=y=2 \%$.

This EDAX result confirms the presence of required elements in the grown compositions with almost all the peaks associated with the element such as $\mathrm{Pb}, \mathrm{Y}, \mathrm{Pr}$ and
Ti. The micro-structural analysis thus suggests that this material prepared is $\mathrm{Pr}$ and $\mathrm{Y}$ substituted $\mathrm{PbTiO}_{3}$ ceramics.

\subsection{Dielectric Characteristics}

Dielectric characterstics indicate its response to an applied electric field. The variation of dielectric constant with temperature at different frequency of applied ac field ranging from $1 \mathrm{KHz}$ to $1 \mathrm{MHz}$ and temperature ranging from room temperature to $450{ }^{\circ} \mathrm{C}$ is shown in Figs. 5a-5d.

From the results, one can observe that the value of dielectric constant $\left(\varepsilon^{\prime}\right)$ increases slowly up to a temperature of $200{ }^{\circ} \mathrm{C}$ in almost all the compositions and then increases sharply till it attains maximum and then start decreasing, thereby suggesting the material to be ferroelectric in nature. The dielectric constant showed a peak at transition temperature for all the compositions and magnitude of peak width was found to depend on the frequency of measurements.

In the light of above observation, one can suggest that material under consideration shows a typical normal ferroelectric behaviour, where $\varepsilon^{\prime}$ increases with temperature due to interfacial polarization which becomes more dominant as compared to dipolar polarization below the Curie temperature. However, with further increase in temperature, $\varepsilon^{\prime}$ starts decreasing due to the phase transition from ferroelectric to paraelectric phase. With increase in $\mathrm{Pr}$ content into PT lattice, the value of $\varepsilon^{\prime}$ was found to increase from 12 to 34 at room temperature and the same trend was obtained for all the frequencies. However, the maximum value of $\varepsilon^{\prime}$ at a frequency of $1 \mathrm{KHz}$ decreases from 2,178 to 1,000 (Table 2) with the increase in praseodymium concentration. This decrease in $\varepsilon_{\text {max }}^{\prime}$ implies that substitution of Pr reduces dipole moment of the lattice and lowers the peak value of dielectric constant. If we concentrate at a frequency of $1 \mathrm{KHz}$ in all the compositions, it is clearly seen that the peak value of dielectric constant decreases and the peak width increases with increase in Pr content. 


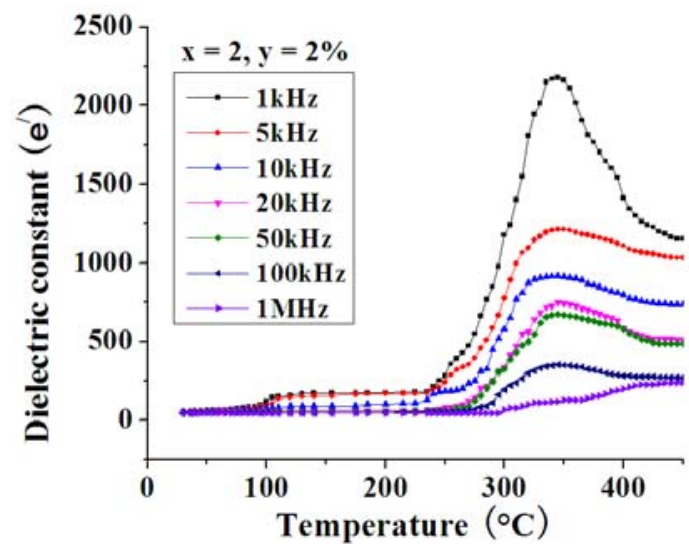

(a)

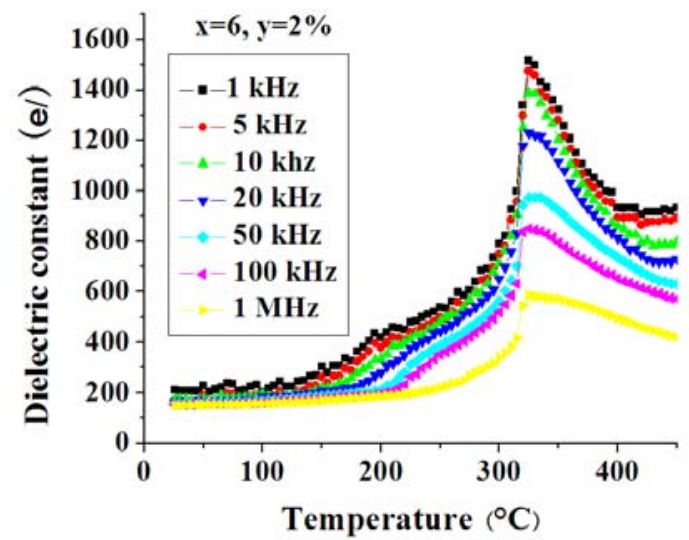

(c)

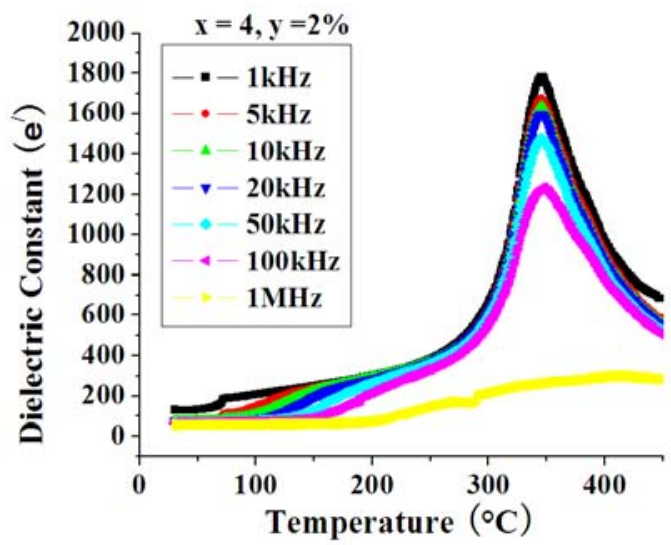

(b)

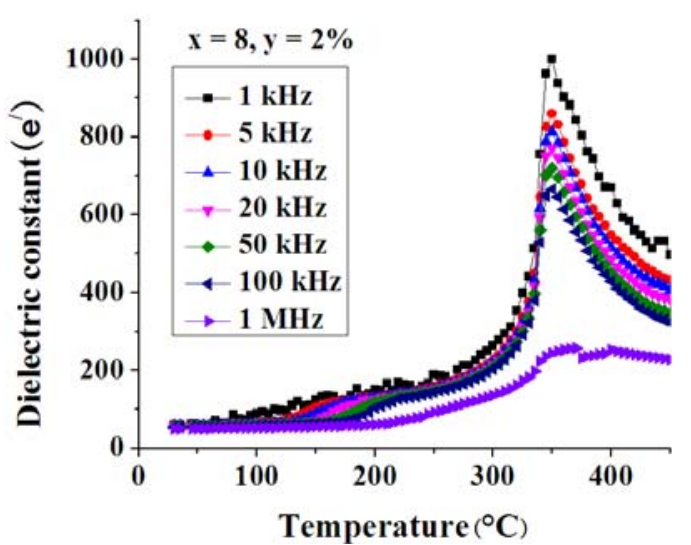

(d)

Fig. 5 Dielectric constant versus temperature of $\mathrm{Pb}_{1-\mathrm{x}} \mathrm{Pr}_{\mathrm{x}} \mathrm{Ti}_{1-\mathrm{y}} \mathrm{Y}_{\mathrm{y}} \mathrm{O}_{3}$ compositions (a) $x=y=2 \%,(b) x=4, y=2 \%,(c) x=6$, $y=2 \%$ and (d) $x=8, y=2 \%$.

Table 2 Values of dielectric constant, Curie temperature, piezoelectric coefficient $\left(d_{33}\right.$ and $\left.g_{33}\right)$ for rare earth double doped lead titanate with compositions $\operatorname{Pb}_{1-\mathrm{x}} \operatorname{Pr}_{\mathrm{x}} \mathrm{Ti}_{1-\mathrm{y}} \mathrm{Y}_{\mathrm{y}} \mathrm{O}_{3}$ where $\mathrm{x}=0.02,0.04,0.06,0.08$ and $y=0.02$.

\begin{tabular}{lllll}
\hline $\begin{array}{l}\text { Compositions } \\
\mathrm{x}=\operatorname{Pr}, \mathrm{y}=\mathrm{Y}\end{array}$ & \multirow{2}{*}{ Dielectric constant $\left(\varepsilon^{\prime}\right)$} & Curie Temperature $\left({ }^{\circ} \mathrm{C}\right)$ & $\begin{array}{l}\text { Piezoelectric charge } \\
\text { Coefficient }\left(\mathrm{d}_{33}\right)(\mathrm{p} \mathrm{c} / \mathrm{N})\end{array}$ & $\begin{array}{l}\text { Piezoelectric voltage } \\
\text { Coefficient }\left(\mathrm{g}_{33}\right)\left(\times 10^{-3} \mathrm{~m} / \mathrm{N}\right)\end{array}$ \\
\hline $\mathrm{x}=0.02, \mathrm{y}=0.02$ & 2,178 & 345 & 26 & 13 \\
$\mathrm{x}=0.04, \mathrm{y}=0.02$ & 1,800 & 343 & 16 & 10 \\
$\mathrm{x}=0.06, \mathrm{y}=0.02$ & 1,514 & 325 & 27 & 21 \\
$\mathrm{x}=0.08, \mathrm{y}=0.02$ & 1,000 & 351 & 19 & 20 \\
\hline
\end{tabular}

Increase in peak width with the increase in La content has already been reported $[23,24]$. Table 2 gives the compiled data for maximum value of dielectric constant and corresponding Curie temperature for all these compositions.

In all the compositions, peak width increases with increase in Pr content, these results into the diffused phase transitions. This may be due to the disorder in the arrangement of rare earth (praseodymium) and other atoms, leading to a microscopic heterogeneity in the composition and thus a distribution of different local
Curie points [25]. The structural disorder arises due to the presence of a number of voids and impurities of different size. The degree of diffusivity $(\gamma)$ can be calculated using the given expression [26] $\ln$ $\left(1 / \varepsilon^{\prime}-1 / \varepsilon_{\max }^{\prime}\right)=\gamma \ln \left(\mathrm{T}-\mathrm{T}_{\mathrm{C}}\right)+\mathrm{C}$; where " $\varepsilon_{\text {max }}^{\prime}$ " is the maximum value of dielectric constant at transition temperature, " $\gamma$ " is the degree of diffusiveness which lies in the range $1<\gamma \leq 2 \gamma=1$ represent the ideal Curie Weiss behaviour, whereas " $\gamma$ " between 1 and 2 indicates diffuse phase transition [27]. The value of " $\gamma$ " is calculated from the slope of graph $\ln \left(1 / \varepsilon^{\prime}-1 / \varepsilon_{\max }^{\prime}\right)$ versus 

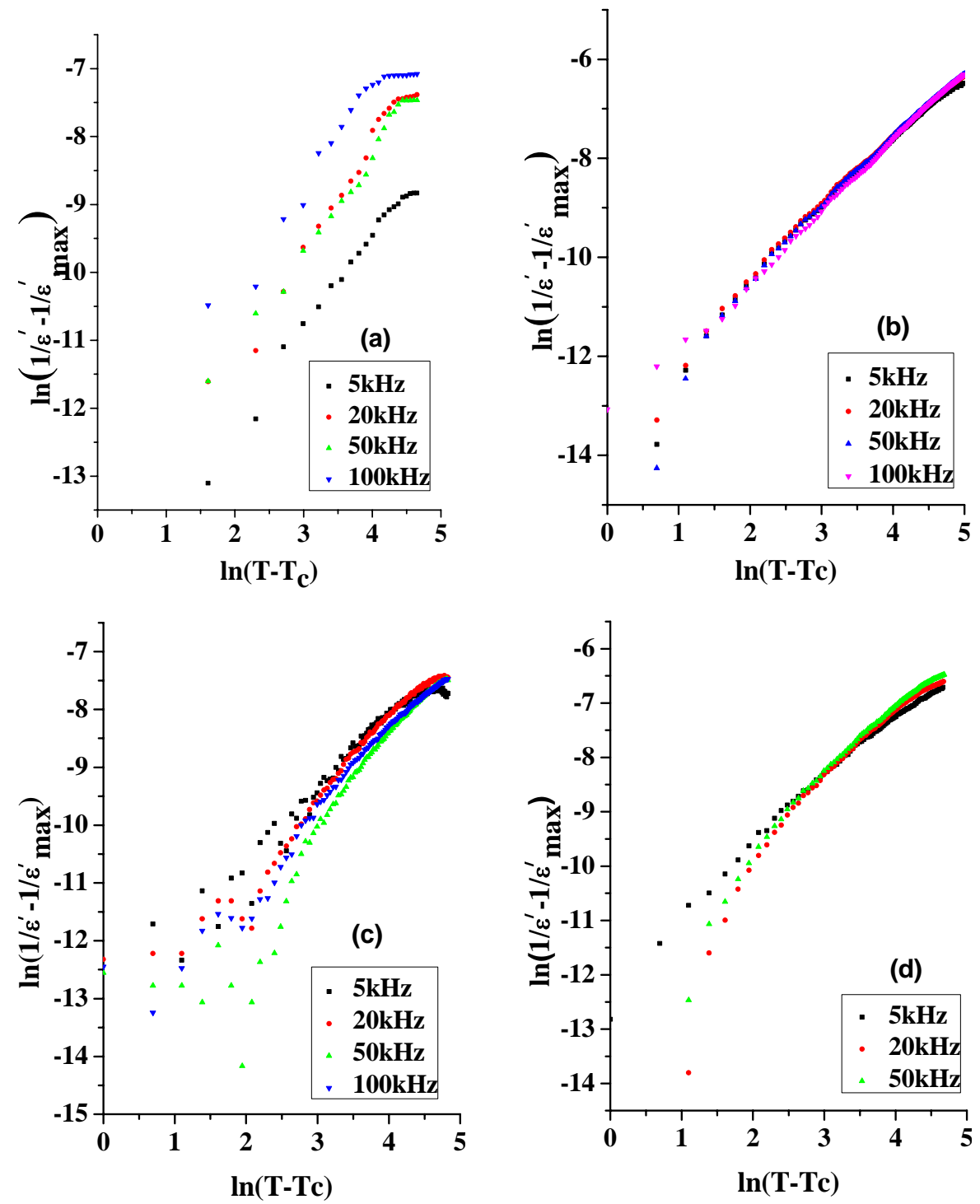

Fig. 6 Diffusivity curves for $\operatorname{Pb}_{1-x} \operatorname{Pr}_{x} \operatorname{Ti}_{1-y} Y_{y} O_{3}$ compositions (a) $x=2, y=2 \%$, (b) $x=4, y=2 \%$, (c) $x=6, y=2 \%$ and (d) $x=8$, $y=2 \%$.

$\ln \left(\mathrm{T}-\mathrm{T}_{\mathrm{C}}\right)$. Fig. 6 (a-d) shows the variation of $\ln \left(1 / \varepsilon^{\prime}-1 / \varepsilon_{\max }^{\prime}\right)$ with $\ln \left(\mathrm{T}-\mathrm{T}_{\mathrm{C}}\right)$ at a particular frequency of $5 \times 10^{3} \mathrm{~Hz}$ for different composition i.e., with $\mathrm{x}$ $($ praseodymium $)=0.02,0.04$. 0.06 and 0.08 and $y$ (yttrium) $=0.02$, and it is found that the value of " $\gamma$ " comes out to be $1.45,1.39,1.14,1.14$, respectively. This implies the diffuse phase transition, which may be due to the compositional fluctuations and structural disordering in the arrangement of cations in one or more crystallographic sites in the structure that finally results in a microscopic heterogeneity in the grown materials with local Curie points [28, 29].

\subsection{Piezoelectric Coefficient}

The values of piezoelectric coefficient were found to be dependent on substitution in the modified lead titanate ceramics. The value of piezoelectric charge coefficient $\left(\mathrm{d}_{33}\right)$ and piezoelectric voltage coefficient $\left(g_{33}\right)$ are given in Table 2. The maximum value of piezoelectric charge coefficient $\left(\mathrm{d}_{33}\right)$ is $27 \mathrm{pc} / \mathrm{N}$ for $\mathrm{x}=6$ and $\mathrm{y}=2 \mathrm{~mol} \%$ substituted PT ceramics, whereas the minimum value of $16 \mathrm{pc} / \mathrm{N}$ was found to be in case of $\mathrm{x}=4, \mathrm{y}=2 \mathrm{~mol} \%$ of modified PT ceramics. The maximum value of $\mathrm{d}_{33}$ in case of $\mathrm{x}=6, \mathrm{y}=2 \mathrm{~mol} \%$ is 
suggested to be due to the reorientation of domains, which is facilitated by decrease in crystal tetragonality [30]. The crystal tetragonality (c/a) was found to be minimum in this composition. This increase in the value of $d_{33}$ has been reported by Xue et al. [19] in samarium doped ceramics. De Frutos and Jimenez [30] reported saturated piezoelectric $d_{33}$ value of $110 \mathrm{pc} / \mathrm{N}$ for calcium modified ceramics and have attributed this to increase in $180^{\circ}$ domain reversal and stress caused by the poling field in higher calcium containing PT ceramics. They have reiterated their result with the addition that the contribution due to stress caused by the polling field has to be taken in to account. In our results, $180^{\circ}$ domain reorientation is found to increase with decreasing tetragonality (c/a) resulting in increases of $180^{\circ}$ domain polarization contribution. Therefore, $d_{33}$ arises due to $180^{\circ}$ domain reversal seems to explain our results. The decrease of $\mathrm{d}_{33}$ for composition exceeding $\mathrm{x}=6 ; \mathrm{y}=2 \mathrm{~mol} \%$ of concentration may be due to the microstructural changes [31, 32]. It could be that the relaxor like properties at the higher $\operatorname{Pr}^{3+}$ concentration may probably account for the decay of piezoelectricity above $\mathrm{x}=6 ; \mathrm{y}=2 \mathrm{~mol} \%$ of substitution. The piezoelectric voltage coefficient $\left(\mathrm{g}_{33}\right)$ is also maximum for $\mathrm{x}=6 ; \mathrm{y}=2 \mathrm{~mol} \%$ composition having a value $21 \mathrm{Vm} / \mathrm{N}$.

\subsection{Ferroelectric Properties}

In order to confirm the ferroelectric behavior of these four compositions, polarization (P) versus electric field (E) i.e., (P-E) loop was observed. Fig. 7 illustrates the PE hysteresis loop for $\mathrm{x}=0.02, \mathrm{y}=0.02$; $\mathrm{x}=0.04, \mathrm{y}=0.02 ; \mathrm{x}=0.06, \mathrm{y}=0.02 ; \mathrm{x}=0.08, \mathrm{y}=0.02$ respectively at room temperature. All the compositions exhibit the P-E hysteresis loop, thereby indicating the ferroelectric nature. The value of spontaneous polarization $\left(\mathrm{P}_{\mathrm{s}}\right)$, remanent polarization $\left(\mathrm{P}_{\mathrm{r}}\right)$ and coercive field $\left(\mathrm{E}_{\mathrm{c}}\right)$ was determined in the form of $2 \mathrm{P}_{\mathrm{s}}$, $2 \mathrm{P}_{\mathrm{r}}$ and $2 \mathrm{E}_{\mathrm{c}}$, respectively, in order to take care of any shifting of PE loop from the origin. These values are given in Table 3. The result of coercive field $\left(\mathrm{E}_{\mathrm{c}}\right)$ and remanent polarization $\left(\mathrm{P}_{\mathrm{r}}\right)$ are correlated with the amount of substitution. It can be seen that the value of $\mathrm{E}_{\mathrm{c}}$ decrease up to $\mathrm{x}=0.06, \mathrm{y}=0.02 \mathrm{~mole} \%$ and thereafter increases. The value of $2 \mathrm{P}_{\mathrm{s}}$ also decreases for $\mathrm{x}=0.06, \mathrm{y}=0.02 \mathrm{~mole} \%$ followed by the increase, where as $2 \mathrm{P}_{\mathrm{r}}$ first decreases up to $\mathrm{x}=0.06, \mathrm{y}=0.02$ mole $\%$ followed by increasing trend for further substitution. This may be due to the smaller atomic displacement of cell content [21] and further increase may be resulted from the dominant effect of Pr amount. The decrease in $\mathrm{E}_{\mathrm{c}}$ with $\mathrm{P}_{\mathrm{r}}$ content causes the material to be softened.

\section{Conclusions}

Praseodymium and yttrium modified lead titanate was successfully prepared by solid-state reaction technique in four different composition. X-ray diffraction analysis confirms that all the compositions are in a single phase with perovskite tetragonal structure. The maximum value dielectric constant decreases from 2,178 for $\mathrm{x}=0.02, \mathrm{y}=0.02$ to 1,000 for $\mathrm{x}=0.08, \mathrm{y}=0.02$. This decrease in maximum value of dielectric constant implies that substitution of $\mathrm{Pr}$ reduces the dipole moment of the lattice. Broadening in the dielectric peak is observed leading to diffuse phase transition. Piezoelectric coefficient shows significantly compositional dependence and maximum value of $\mathrm{d}_{33}$ and $\mathrm{g}_{33}$ is found to be $27 \mathrm{pc} / \mathrm{N}$ and $21 \times 10^{-3} \mathrm{Vm} / \mathrm{N}$

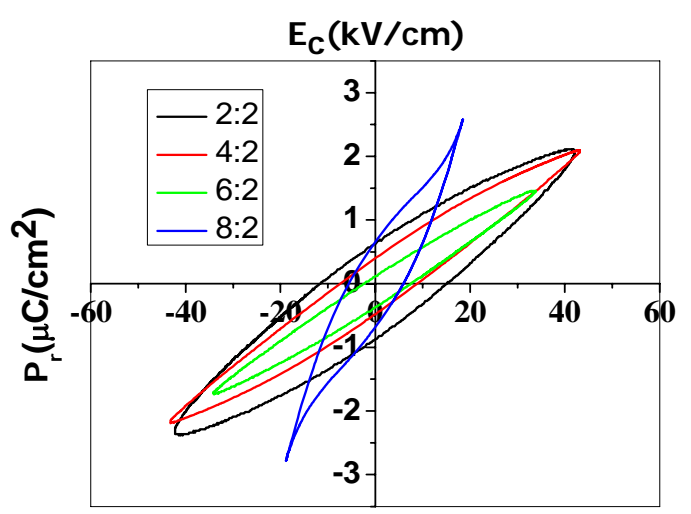

Fig. 7 PE loop of $\operatorname{Pb}_{1-\mathrm{x}} \mathrm{Pr}_{\mathrm{x}} \mathrm{Ti}_{1-\mathrm{y}} \mathrm{Y}_{\mathrm{y}} \mathrm{O}_{3}$ compositions for $\mathrm{x}=0.02, \mathrm{y}=0.02 ; \mathrm{x}=0.04, \mathrm{y}=0.02 ; \mathrm{x}=0.06, \mathrm{y}=0.02$; $\mathrm{x}=0.08, \mathrm{y}=0.02$. 
Table 3 The values of spontaneous polarization $\left(2 P_{s}\right)$, remanent polarization $\left(2 P_{r}\right)$ and coercive field $\left(2 E_{c}\right)$ for rare earth double doped lead titanate with compositions $\operatorname{Pb}_{1-\mathrm{x}} \mathrm{Pr}_{\mathrm{x}} \mathrm{Ti}_{1-\mathrm{y}} \mathrm{Y}_{\mathrm{y}} \mathrm{O}_{3}$ where $\mathrm{x}=0.02,0.04,0.06,0.08$ and $y=0.02$.

\begin{tabular}{llll}
\hline $\mathrm{x}=\mathrm{Pr}, \mathrm{y}=\mathrm{Y}$ & Spontaneous Polarization, $2 \mathrm{P}_{\mathrm{s}}\left(\mu \mathrm{C} / \mathrm{cm}^{2}\right)$ & Remanance, $2 \mathrm{P}_{\mathrm{r}}\left(\mu \mathrm{C} / \mathrm{cm}^{2}\right)$ & Coercitivity, 2 $\mathrm{E}_{\mathrm{c}}(\mathrm{kV} / \mathrm{Cm})$ \\
\hline $\mathrm{x}=0.02, \mathrm{y}=0.02$ & 4.46 & 1.58 & 27.74 \\
$\mathrm{x}=0.04, \mathrm{y}=0.02$ & 4.26 & 0.85 & 16.46 \\
$\mathrm{x}=0.06, \mathrm{y}=0.02$ & 3.58 & 0.48 & 9.95 \\
$\mathrm{x}=0.08, \mathrm{y}=0.02$ & 5.35 & 1.36 & 11.52 \\
\hline
\end{tabular}

respectively for $\mathrm{x}=0.06, \mathrm{y}=0.02$. The coercitivity decrease with the increase of Pr content. Decrease in Ec shows that material softens with the increase of $\mathrm{Pr}$ substitution.

\section{Acknowledgments}

The author's are thankful to Instrumentation Centre, Indian Institute of Technology, Roorkee for providing XRD and electron microscopic facilities.

\section{References}

[1] T. Takahashi, Lead titanate ceramics with large piezoelectric anisotropy and their application Ceram, Bull 69 (1990) 691-695.

[2] R.N. Schwartz, B.A. Wechsler, L. West, Spectroscopic and photorefractive properties of molybdenum-doped barium titanate, Appl. Phys. Lett. 67 (1995) 1352-1356.

[3] G. Shirane, S. Hoshino, On the phase transition in lead titanate, J. Phys. Sco. Jpn. 6 (1951) 265-270.

[4] B. Jaffe, R.S. Roth, S. Marzullo, Properties of piezoelectric ceramics in the solid-solution series lead titanate-lead zirconate-lead oxide, tin oxide and lead titanate-lead hafnate, J. Res. Nat. Bull Stand 55 (1955) 229-254.

[5] A. Udomporn, K. Pengpat, S. Ananta, Highly dense lead titanate ceramics from refined processing, J. Eur. Ceram. Soc. 24 (2) (2004) 185-188.

[6] R. Wongmanccrung, R. Ymmirun, S. Ananta, Effects of sintering condition on phase formation, microstructure and dielectric properties of lead titanate ceramics, J. Appl. Phys. A 80 (2) (2007) 249-255.

[7] T.Y. Tein, W.G. Carlron, Effect of additives on properties of lead titanate, J. Am. Ceram. Soc. 45 (1962) 567-571.

[8] G. Evans, E.A. Charls, Fracture toughness determinations by indentation, J. Am. Ceram. Soc. 59 (1976) 371-372.

[9] H. Takeuchi, S. Jyomura, C. Nakaya, New piezoelectric materials for ultrasonic transducers, Jpn. J. Appl. Phy. 24 (1985) 36-40.

[10] T. Suwannasiri, A. Safari, Effect of rare-earth additives on electromechanical properties of modified lead titanate ceramics, J. Am. Ceramic Society 76 (1993) 3155-3158.
[11] N. Ichinose, Y. Fuse, Anisotropy of piezoelectric properties in the modified $\mathrm{PbTiO}_{3}$ ceramics, Ferroelectrics 106 (1990) 369-374.

[12] S. Ikegami, I. Ueda, T. Nagata, Electromechanical properties of $\mathrm{PbTiO}_{3}$ ceramics containing $\mathrm{La}$ and $\mathrm{Mn}, \mathrm{J}$. Acoust. Soc. Am. 50 (1971) 1060.

[13] O. Ohnishi, H. Kishie, A. Iwamoto, Y. Sasaki, T. Zaitsu, T. Inoue, A lead free piezoelectric transformer in radial vibration modes, in: IEEE, Ultrason. Symp. 1 (1992) 483.

[14] S.Y. Chu, C.H. Chen, Effect of calcium on the piezoelectric and dielectric properties of Sm-modified $\mathrm{PbTiO}_{3}$ ceramics, Sensors and Actuators A 89 (2001) 210-214.

[15] Y. Yamashita, S. Yoshida, T. Takahashi, Effects of MnO additive on piezoelectric properties in modified $(\mathrm{Pb}, \mathrm{Ca}) \mathrm{TiO}_{3}$ ferroelectric ceramics, Jpn. J. Appl. Phy. 22 (1983) 40-42.

[16] R. Tickoo, R.P. Tandon, K.K. Bamzai, P.N. Kotru, Dielectric and piezoelectric characteristics of Sm modified lead titanate ceramics, Mater. Sci. Eng B 103 (2003) 145-151.

[17] V. Singh, K.K. Bamzai, S. Suri, N. Nidhi, Preparation, structural and electrical characterization of praseodymium modified lead titanate, Ceramic International 37 (2011) 2655-2662.

[18] S. Chu, C. Chems, Effects of dopants on the piezoelectric and dielectric properties of Sm-modified $\mathrm{PbTiO}_{3}$ ceramics, Mater. Res. Bull. 35 (2000) 2317-2324.

[19] W.R. Xue, W.A. Schuze, R.E. Newnham, Effects of $\mathrm{Sm}_{2} \mathrm{O}_{3}$ and $\mathrm{Gd}_{2} \mathrm{O}_{3}{ }^{+} \mathrm{Nd}_{2} \mathrm{O}_{3}$ on electromechanical properties of $\mathrm{PbTiO}_{3}$ ceramics, J. Am. Ceram. Soc. 73 (1990) 1783-1784.

[20] D. Hennings, K.H. Hardtl, The distribution of vacancies in lanthanum-doped lead titanate, Phys. Sat. Sol. A (3) (1970) 465-474.

[21] J. Mendiola, B. Jimenez, C. Alemany, L. Pardo, L.D. Olmo, Influence of calcium on the ferroelectricity of modified lead titanate ceramics, Ferroelectrics 94 (1989) 183-188.

[22] R. Tickoo, R.P. Tandon, N.C. Mehra, P.N. Kotru, Dielectric and ferroelectric properties of lanthanum modified lead titanate ceramics, Mat. Sci. Eng. B 94 (2002) $1-7$.

[23] C. Desai, A.H. Patel, M.S.V. Ramana, Studies on 


\section{Praseodymium Doped Lead Titanate Ceramics}

electrical conduction and dielectric properties of ferroelectric lead nitrate phosphate and rubidium hydrogen tartrate single crystals, Ferroelectrics 102 (1990) 22-31.

[24] V. Hangloo, R. Tickoo, K.K. Bamzai, P.N. Kotru, Dielectric characteristics of mixed Gd-Ba molybdate crystals grown at ambient temperatures by the gel encapsulation technique, Mat. Chem. Phys. 81 (2003) 152-159.

[25] M.E. Lines, A.M. Glass, Principle and Application of Ferroelectric and Related Materials, Oxford, 1997.

[26] S.M. Pilgrim, Diffuseness as a useful parameter for relaxor ceramics, J. Am. Ceram. Soc. 73 (1990) 3122-3125.

[27] K. Prasad, Diffuse phase transition in perovskite ferroelectrics, Indian J. Eng. Mater. Sci. 7 (2000) 446-450.
[28] L.E. Cross, Relaxor ferroelectrics, Ferroelectrics 76 (1987) 241-267.

[29] C. Schmidt, Diffusive phase transitions, Ferroelectrics 78 (1988) 199-206.

[30] J.D. Frutos, B. Jimenez, Evolution of the spatial distribution of polarization in lead-calcium ferroelectric ceramics, Ferroelectrics 126 (1992) 341-345.

[31] G.A. Rossetti Jr, W. Cao, C.A. Raddall, Microstructural characteristics and diffuse phase transition behavior of lanthanum-modified lead titanate, Ferroelectrics 158 (1994) 343-350.

[32] A. Raddall, G.A. Rossetti, W. Cao, Spatial variations of polarization in ferroelectrics and related materials, Ferroelectrics 150 (1993) 163-169. 